\title{
Economic Indicators
}

\begin{tabular}{|c|c|c|c|c|c|}
\hline PRICES AND INFLATION & Value & Period & $\begin{array}{l}\text { Monthly } \\
\text { change }\end{array}$ & $\begin{array}{l}\text { Annual } \\
\text { change }\end{array}$ & $\begin{array}{l}\text { Release } \\
\text { date }\end{array}$ \\
\hline Consumer Prices Index (CPI) $(2005=100)$ & 116.8 & Dec-10 & 1.0 & 3.7 & 18-Jan-11 \\
\hline $\begin{array}{l}\text { Retail Prices Index (all items) (Jan } \\
\text { 1987=100) }\end{array}$ & 228.4 & Dec-10 & 0.7 & 4.8 & 18-Jan-11 \\
\hline $\begin{array}{l}\text { RPI excluding mortgage interest (RPIX) (Jan } \\
1987=100)\end{array}$ & 227.5 & Dec-10 & 0.7 & 4.7 & 18-Jan-11 \\
\hline Producer Prices Index - Output $(2005=100)$ & 121.1 & Jan-11 & 1.0 & 4.8 & $11-$ Feb-11 \\
\hline $\begin{array}{l}\text { Producer Prices Index - Input prices } \\
\text { (materials and fuel) }(2005=100)\end{array}$ & 158.4 & Jan-11 & 1.7 & 13.4 & $11-$ Feb-11 \\
\hline LABOUR MARKET & Value & Period & $\begin{array}{l}\text { Change on } 3 \\
\text { months }\end{array}$ & $\begin{array}{l}\text { Change on } 1 \\
\text { year }\end{array}$ & $\begin{array}{l}\text { Release } \\
\text { date }\end{array}$ \\
\hline Employment rate $(\%)$ & 70.4 & Sep-Nov 10 & -0.3 & -0.1 & 19-Jan-11 \\
\hline Unemployment rate (\%) & 7.9 & Sep-Nov 10 & 0.2 & 0.1 & 19-Jan-11 \\
\hline Average Weekly Earnings - total pay (\%) & 2.1 & Sep-Nov 10 & 0.4 & 1.4 & 19-Jan-11 \\
\hline Average Weekly Earnings - regular pay (\%) & 2.3 & Sep-Nov 10 & 0.3 & 1.2 & 19-Jan-11 \\
\hline $\begin{array}{l}\text { Claimant count (Jobseeker's Allowance) } \\
\text { (Thousands) }(2005=100)\end{array}$ & $1,456.6$ & Dec-10 & -12.5 & -144.0 & 19-Jan-11 \\
\hline Vacancies (Thousands) & 480 & Oct-Dec 10 & 18 & 14 & 19-Jan-11 \\
\hline $\begin{array}{l}\text { NATIONAL ACCOUNTS ECONOMIC } \\
\text { ACTIVITY }\end{array}$ & Value & Period & $\begin{array}{l}\text { Quarterly } \\
\text { change }\end{array}$ & $\begin{array}{l}\text { Change on } 1 \\
\text { year }^{3}\end{array}$ & $\begin{array}{l}\text { Release } \\
\text { date }\end{array}$ \\
\hline $\begin{array}{l}\text { UK Gross Domestic Product (chained volume } \\
\text { measure } £ \text { billion) }\end{array}$ & 329.6 & Q4 10 & -0.5 & 1.7 & 25-Jan-11 \\
\hline $\begin{array}{l}\text { Private Non-Financial Corporations Net } \\
\text { Lending ( } £ \text { billion) }\end{array}$ & 15.8 & Q3 10 & & & 22-Dec-10 \\
\hline Household Saving Ratio (\%) & 5.0 & Q3 10 & & & 22-Dec-10 \\
\hline Public Sector current budget ( $£$ billion) & -13.5 & Dec-10 & & & 25-Jan-11 \\
\hline Public Sector net debt as a \% of GDP & 58.0 & Nov-10 & & & 21-Dec-10 \\
\hline Public Sector net borrowing ( $£$ billion) & 10.3 & Oct-10 & & & 25-Jan-11 \\
\hline Public Sector net cash requirement ( $£$ billion) & 16.8 & Dec-10 & & & 25-Jan-11 \\
\hline $\begin{array}{l}\text { Public sector net borrowing (excluding } \\
\text { financial interventions) ( } £ \text { billion) }\end{array}$ & 59.3 & Dec-10 & & & 25-Jan-11 \\
\hline
\end{tabular}


Public sector net debt as a $\%$ of GDP (excluding financial interventions)

59.3

Dec-10

25-Jan-11

BALANCE OF PAYMENTS AND TRADE
UK's trade balance ( $£$ billion)
Balance of Payments current account - ( $£$
billion)
of which: EU
non-EU
Goods export volumes - excluding oil and
erratics $(2006=100)$

Goods import volumes - excluding oil and erratics $(2006=100)$

Value
$-£ 4.8$
$-£ 9.6$
$-£ 3 . .8$

96.1 Dec-10
Change on 3 Change on 1 Release months year date

$-£ 4.8 \quad$ Nov-10 9-Feb-11

-£9.6 Q3 $10 \quad$ 22-Dec-11

$£ 12.8$

$£ 3.2$

89.5 Dec-10

9-Feb-11

9-Feb-11

\section{SHORT TERM INDICATORS}

Value

Period
Change on 3 months ${ }^{1}$

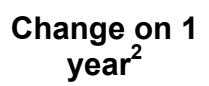

Release

$0.2 \quad 0.4 \quad 21-J a n-11$

Retail Sales $(2006=100)$ (chained volume,

107.7

Dec-10

91.9 Dec-10

1.2

5.4

10-Feb-11

90.4 Dec-10

0.8

3.5

10-Feb-11

99.6

Q3 10

0.1

1.7

23-Dec-10

106.6

Q3 10

0.8

8.0

23-Dec-10

102.4

Nov-10

0.5

1.9

Notes:

1. Three months on previous three months

2. Three months on corresponding period one year ago

3. Quarter on corresponding period one year ago 